\title{
Paleolimnological puzzles, databases and aquatic transitions
}

\author{
Keely Mills', P. Gell ${ }^{2}$ and J. Saros ${ }^{3}$
}

Bangor, USA, 26-28 April 2016

The second meeting of PAGES' Aquatic Transitions working group, held at the University of Maine, was attended by 23 members, including 16 new representatives from the UK, US, Canada, India, and Argentina. Given the number of new faces at the meeting, the workshop opened with short introductory presentations from the new participants, leading nicely into a recap on the outcomes and updates from the previous meeting in 2015 (Mills and Gell 2015).

Updates were also provided on a number of manuscripts currently in preparation. The manuscript "Modeling regime shifts in lake sediments" (led by Z. Taranu and M. Perga) stimulated much discussion among new members, and S. Juggins and G. Simpson provided fantastic statistical guidance with regards to the identification of "transitions" in paleolimnological archives. The review paper, by 24 members of the working group and led by N. Dubois, titled "Early human impacts of lakes and wetlands" is a large undertaking. The authors present at the meeting worked on the draft, the focus of the conclusions, and proposed additional sections to ensure a global perspective.

Prior to the workshop, K. Mills and P. Gell were invited by "Wiley Interdisciplinary
Reviews (WIREs): Water" to write an overview paper on long-term changes in lake systems. We used this meeting as a sounding board for ideas and inputs, and outlined the nowpublished paper "Deciphering long-term records of natural variability and human impact as recorded in lake sediments: a palaeolimnological puzzle" which is co-authored by 15 members of the Aquatic Transitions community (Mills et al. 2017; Fig. 1).

J.-P. Jenny led a discussion on the content and nature of the data required to achieve the goals of Aquatic Transitions, and whether the overlap with other core working groups' databases (from PAGES 2k Network or the former Varves Working Group, for example) was an impetus for a joint effort, as opposed to "reinventing the wheel" for similar data collection.

Other key outputs from this meeting included the outline of a book proposal for the Springer series "Developments in Paleoenvironmental Research", in response to an invitation from the publisher. A session proposal was also written and submitted to the International Association for Ecology's (INTECOL) International Wetlands Conference (IWC) that was held in Changshu, China, in September 2016. This conference was a fantastic opportunity to broaden the membership of Aquatic Transitions in South East Asia, and the conference also opened up the opportunity to engage with key stakeholders (including Ramsar, catchment managers and other practitioners in water management). S. McGowan and K. Mills, who attended this meeting, wrote a report for the British Geological Survey's blogsite "Geoblogy" (McGowan and Mills 2016). The success of the INTECOL IWC session led to the next Aquatic Transitions meeting in Malaysia in February 2017, which focused on enhancing the understanding of freshwater systems in SE Asia.

\section{AFFILIATIONS}

'British Geological Survey, Keyworth, UK

2Water Research Network, Federation University Australia, Ballarat, Australia

${ }^{3}$ Climate Change Institute, University of Maine, Bangor, USA

\section{CONTACT}

Peter Gell: p.gell@federation.edu.au

REFERENCES

McGowan S, Mills K (2016) INTECOL International Wetlands conference in Changshu, China. Geoblogy

Mills K, Gell P (2015) PAGES Mag 23: 70

Mills K et al. (2017) WIREs Water 4: e1195

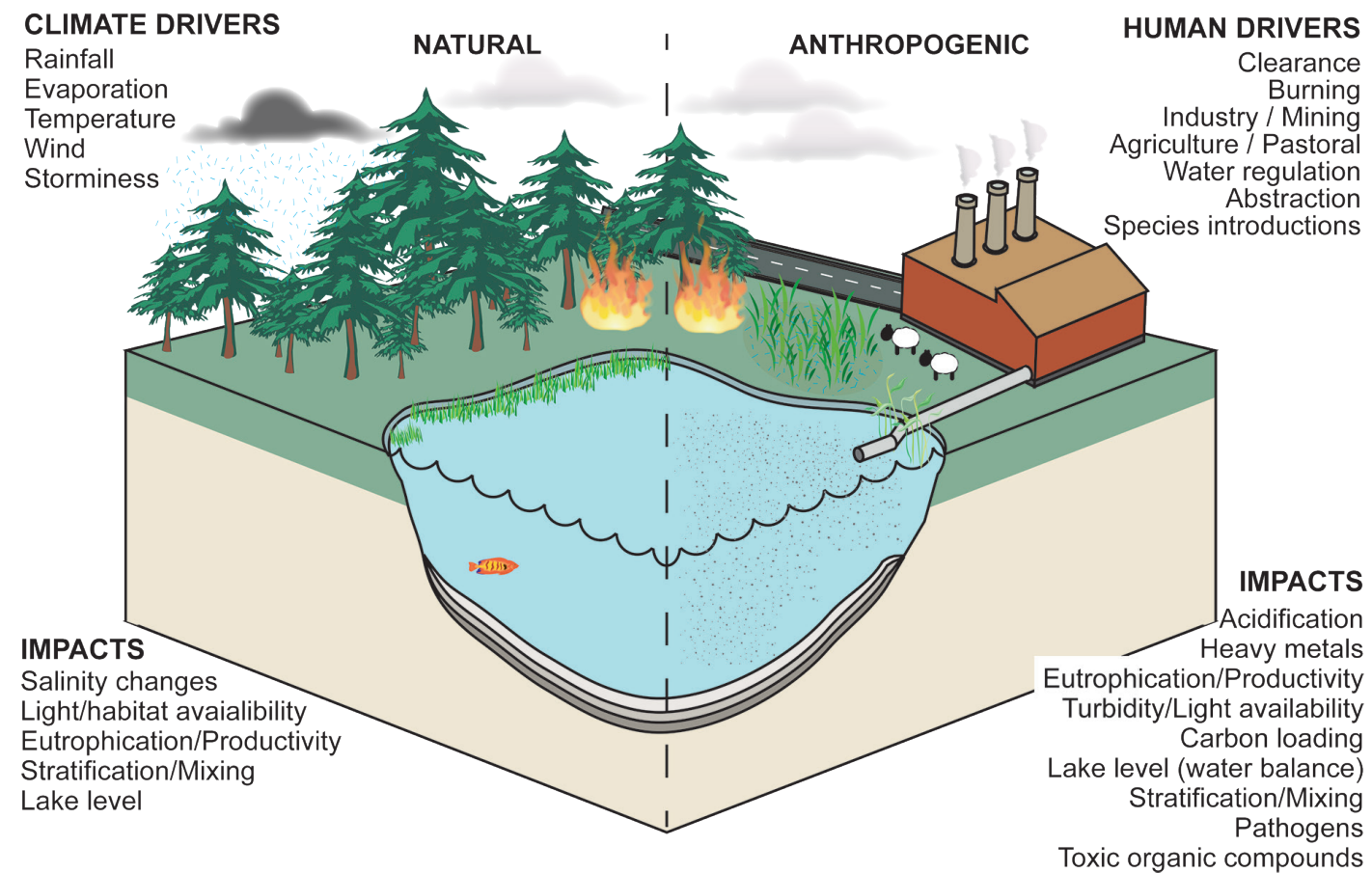

Figure 1: Identifying transitions in lake sediment sequences is complex, not least because both climate and humans can cause changes in lake systems that manifest in a similar fashion in the lake sediment archive. Reprinted from Mills et al. (2017) with authorization from BGS () NERC 2017. 